\title{
СИМПТОМАТИЧЕСКАЯ ФОКАЛЬНАЯ ЭПИЛЕПСИЯ С ФЕНОМЕНОМ ВТОРИЧНОЙ БИЛАТЕРАЛЬНОЙ СИНХРОНИЗАЦИИ НА ЭЭГ
}

${ }^{1}$ Гаджиева А.Р., ${ }^{2}$ Королева Н.Ю., ${ }^{2}$ Некрасова В.В.

${ }^{1}$ Кафедра нервных болезней Азербайджсанского Государственного Института Усовершенствования врачей им.А. Алиева, Баку;

${ }^{2}$ Центр Видео-ЭЭГ мониторинга и неврологии ЛДЦ МИБС, Санкт-Петербург.

Один из самых актуальных в настоящее время вопросов эпилептологии - дихотомическое деление эпилепсий на фокальные и генерализованные. Широко известен факт, что фокальные формы эпилепсии нередко "мимикрируют" генерализованные формы за счет феномена вторичной билатеральной синхронизации и диффузного распространения эпилептической активности с развитием приступов, которые визуально, по кинематике приступа, могут быть расценены как генерализованные. Это явление широко распространено у пациентов с симптоматическими формами эпилепсии, особенно в младенческом и раннем детском возрасте (фокальные "маски" синдрома Отахара, Веста, Леннокса-Гасто и др.).

Симптоматические фокальные формы эпилепсии нередко "маскируются" под идиопатические формы (как фокальные, так и генерализованные). В ряде случаев приступы, по внешним характеристикам напоминающие типичные генерализованные, могут иметь на самом деле фокальный генез (т.е. возникают за счет явления вторичной билатеральной синхронизации с диффузным распространением эпилептиформной активности). Данный феномен послужил основной для определения понятия "псевдогенерализованные" приступы (Мухин К.Ю. и соавт., 2006, Воронкова К.В.2010).

Под псевдогенерализованными подразумеваются приступы, имеющие кинематические характеристики генерализованных, диффузные иктальные ЭЭГ паттерны, но по механизму возникновения являющиеся фокальными. В основе их возникновения лежит патофизиологический феномен вторичной билатеральной синхронизации.

"Билатеральная синхронизация" имеет место при одновременном возникновении идентичных ЭЭГ паттернов от гомологичных электродов обеих гемисфер. Она может быть "первичной" при идиопатических генерализованных формах эпилепсии, обусловленных диффузной мембранной нестабильностью (каналопатия) [7,9] и "вторичной" в рамках идиопатических и симптоматических фокальных эпилепсий, то есть развиваться из унилатерального коркового фокуса $[5,6,15]$.

Современное определение феномена вторичной билатеральной синхронизации было дано Blume \& Pillay в 1985 году [6]. Авторы обозначили ВБС как "ЭЭГ паттерн, состоящий из последовательности спайков, полиспайков, или пик - волновых комплексов, гораздо реже медленных волн, сразу после которых следует вспышка билатеральных синхронных и симметричных пик волновых комплексов с широким распространением на обе гемисферы... при этом данный феномен должен в неизменном виде повторяться хотя бы дважды в течение короткого периода одной записи ЭЭГ".

Вторичная билатеральная синхронизация представляет собой нередкий феномен, определяемый при ЭЭГ исследовании у больных эпилепсией. Согласно данным Bureau \& Maton (1998) [8], ВБС определялась у $36 \%$ обследованных больных с криптогенной и симптоматической фокальной эпилепсией. Во всех публикациях подчеркивается преимущественно детский и подростковый возраст больных с феноменом 
ВБС [6,9]. По мнению Blume \& Pillay [6], ВБС достоверно чаще встречается в рамках симптоматической лобной эпилепсии.

Феномен ВБС имеет большое практическое значение. При любой форме эпилепсии обнаружение ВБС на ЭЭГ знаменует возможность появления в клинике новых типов приступов, возникновение или углубление когнитивных расстройств и, в целом, менее благоприятный прогноз. Характер приступов, ассоциированных с ВБС, изучен недостаточно. Подчеркивается крайний полиморфизм приступов и высокая частота приступов. Описаны следующие основные типы эпилептических приступов у больных с ВБС: генерализованные тонико-клонические, атонические, абсансы, тонические и миоклонические $[4,5,6,7]$.

Появление ВБС на ЭЭГ также диктует необходимость пересмотра тактики лечения пациентов. Парадокс заключается в том, что данный феномен на ЭЭГ встречается при фокальных формах эпилепсии, а антиэпилептические препараты (АЭП), традиционно применяемые в лечении фокальных эпилепсий, не рекомендованы при появлении ВБС. Назначение таких препаратов, как карбамазепин, габапентин, при обнаружении ВБС, может вызвать учащение приступов, появление нового типа приступов, нарастание когнитивных нарушений [1].

Клинический случай - пациент В. 28 лет обратился к нам в апреле 2012 года с жалобами на генерализованные тонико-клонические приступы частотой 2 - 3 раза в год, редкие массивные двухсторонние миоклонии рук, а также недавно присоединившиеся длительные эпизоды спутанного сознания, во время которых он уходит из дома и через несколько часов оказывается в незнакомом месте.

Болен с 2003 года, когда в возрасте 18 лет вскоре после пробуждения впервые в жизни возник генерализованные тонико-клонический приступ. После этого в течение 3-х лет в утренние часы имели место массивные двух- сторонние миоклонии рук, которые пациент как приступы не расценивал. В 2007 году на фоне стресса утром развился генерализованный судорожный приступ, заставивший пациента обратится к врачу. Была проведена рутинная ЭЭГ, которая не выявила эпилептиформной активности. Наличие 2-х приступов в анамнезе послужила причиной для назначения карбамазепина в дозе 200 мг в сутки лечащим врачом. На фоне приема последнего произошло учащение судорожных приступов до 2-3 раз в год. Но, несмотря на это дозу карбамазепина вновь увеличили до 1200 мг в сутки.

При осмотре пациента отклонений в неврологическом и в психическом статусе не выявлено.

При проведении ночного видео-ЭЭГ-мониторинга во сне на кафедре нервных болезней Азербайджанского Государственного Института Усовершенствования врачей им. А.Алиева выявлена эпилепиформная активность в виде диффузных разрядов комплексов "острая-медленная волна" и "полипик-медленная волна", крайне редко в лобно-центральных отделах имели место одиночные разряды комплексов "остраямедленная волна", фенотипически соответствующие разрядам, характерным для юношеской миоклонической эпилепсии.

Наличие региональных разрядов было расценено как признак фокализации вследствие длительной и неадекватной терапии. Однако, после проведения высокоточной магнитно-резонансной томографии головного мозга по программе эпилепсия в Центре Видео-ЭЭГ мониторинга и неврологии ЛДЦ МИБС было выявлено 2 субэпиндемальных очага гетеротопии в области передних рогов обоих желудочков головного мозга.

Учитывая клинические данные, и данные Видео-ЭЭГ-мониторинга результаты МРТ (порок развития головного мозга) пациенту был поставлен диагноз: Симптоматическая фокальная эпилепсия (Фенотипи- 
ческая копия юношеской миоклонической эпилепсии).

Учитывая клинические проявления и особенности эпилептиформной активности на ЭЭГ, пациенту был назначен вальпроат натрия в дозе 1250 мг в сутки с последующей постепенной отменой карбамазепина.

Через 6 месяцев при повторном визите приступов не отмечалось. При проведении контрольного Видео-ЭЭГ-мониторинга во сне были зарегистрированы единичные диффузные разряды комплексов "остраямедленная волна".

Учитывая неполную ремиссию эпилепсии - на ЭЭГ сохранялась диффузная эпилептиформная активность при нормальной терапевтической дозе вальпроатов в

\section{СПИСОК ЛИТЕРАТУРЫ}

1. Карлов В.А., Гнездицкий В.В. Абсансная эпилепсия у детей и взрослых. М.: Прессервис, 2005.

2. Мухин К.Ю., Миронов МБ., Тысячина М.Д., Алиханов А.А., Петрухин А.С.. Электро-клиническая характеристика больных симптоматической фокальной эпилепсией с феноменом вторичной билатеральной синхронизации на ЭЭГ. Русский журнал детской неврологии, том 1, выпуск 1. 2006. стр 6-17. 3. Agostini Mark A., Garcia Maria C., Diaz-Arrastia Ramon, Van Ness Paul C.. Neurology, U.T. Southwestern Medical Center, Dallas. Clinical, electroencephalographic and neuroradiologic characteristics of secondary bilateral synchrony in localization-related epilepsy. Epilepsia 43 Suppl. 7: 34 (Abst. 1.090 ), 2002. 4. Beamanoir A, Mira L. Secondary bilateral synchrony significant EEG pattern in frontal lobe seizures. In Frontal Lobe Seizures and Epilepsies in Children. Milan, Italy: John Libby Eurotext 2003:195-205.

5. Blume WT, Pillay N. Electrographic and clinical correlates of secondary bilateral synchrony. Epilepsia $1985 ; ; 26: 636-41$.

6. Gobbi G, Tassinari CA, Roger J, et al. Particularites electroencephalographicques des epilepsies partielles symptomatiques de l'enfant. Neurol Physiol Clin 1989;19:209-18.

7. Janz D. Juvenile myoclonic epilepsy (Janz syndrome)

- a frontal lobe epilepsy? Epilepsia 2004; 45 (Suppl.3):47.

8. Jasper H. Etude anatomo-physiologique des epilepsies. плазме крови (80 мг/л), был введен в терапию топирамат. Титрация препарата была начата с 25 мг и доведена до 150 мг/сутки.

При проведении контрольного ВидеоЭЭГ-мониторинга через 3 месяца эпилептиформная активность на ЭЭГ нивелировалась.

Выводы: применение современных методов диагностики эпилепсии - Видео-ЭЭГмониторинга и МРТ по программе эпилепсия позволило провести точный дифференциальный диагноз и выявить фенотипическую копию юношеской миоклонической эпилепсии. Комбинация топирамата с препаратами вальпроевой кислоты показала высокую эффективность в терапии симптоматической эпилепсии у пациента с пороками развития головного мозга.

Electroenctphalogr. Clin Neurophysiol 1951;3(2):99-111. 9. Kobayashi K. Ohtsuka Y. Oka E. Ohtahara S. Primary and secondary bilateral synchrony in epilepsy: differentiation by estimation of interhemispheric small time differences during short spike-wave activity. Electroencephalogr Clin Neurophysiol. 1992 Aug;83(2):93-103. 10. Kobayashi K., Maniwa S., Ogino T., Yoshinaga H., Ohtsuka Y., Oka E.. Myoclonic seizures combined with partial seizures and probable pathophysiology of secondary bilateral synchrony. Clin Neurophysiol.2000 Oct;111(10):1813-6.

11. Koepp MJ. Juvenile myoclonic epilepsy - a generalized epilepsy syndrome? Acta Neurol Scand2005: 112 (Suppl. 181): 57-62.

12. Konishi T,Matsuzawa J, Hongou K, Murakami M, Yamatani M, Yagi S. Partial seizures during the course in patients with absence epilepsy. No To Hattatsu.1999 Sep;31(5):395-401.

13. Kubota F, Shibata N, Shiihara Y,Takahashi S,Ohsuka T. Frontal lobe epilepsy with secondarily generalized $3 \mathrm{~Hz}$ spike-waves: a case report. Clin Electroencephalogr. 1997 Jul;28(3):166-71.

14. Millan E.; Abou-Khalil B.; Delbeke D.; Konrad P. Frontal Localization of Absence Seizures Demonstrated by Ictal Positron Emission Tomography. Epilepsy $\&$ Behavior, Volume 2, Number 1, February 2001, pp. 54-60(7).

15. Perucca E, Gram L, Avanzini G, et al. Antiepileptic drugs as a cause of worsening seizures. Epilepsia 1998;39(1):5-17. 